\title{
Experimental studies of the parameters of a positional sprinkler system
}

\author{
Mikhail Kostenko ${ }^{1}$, Vladimir Teterin ${ }^{1}$, Dmitry Melnichuk ${ }^{1, *}$, Sergei Mitrofanov ${ }^{1}$, and Alexey \\ Podyablonskiy ${ }^{2}$ \\ ${ }^{1}$ Institute for Technical Support of Agriculture - a branch of Federal Scientific Agro-Engineering Center \\ VIM, 38/11, Shchors str., 390025, Ryazan, Russia \\ ${ }^{2}$ Academy of law and management of the Federal penitentiary service, 1, Sennaya str., 390000, Ryazan, \\ Russia
}

\begin{abstract}
The most important factor affecting the yield of agricultural crops is the formation of an optimal water regime in the active soil layer. One of the main methods of carrying out such works is sprinkling, since it is closest to the process of natural precipitation. At the same time, existing water sprinklers do not provide watering agricultural lands that meets agrotechnological requirements due to the design features and the specifics of the landscape on which they are used, forming in the process of watering zones with excessive and insufficient moisture. In this regard, a positional water sprinkler has been developed, which has the ability to water along a path close to rectangular. Obtaining this trajectory is achieved due to the design features obtained as a result of mathematical modeling. The article presents the structural diagram of the developed water sprinkler, considers the principle of its operation, presents the results of mathematical analysis and modeling of kinematic processes occurring during its operation. The above research results show that the use of the proposed water sprinkler will improve the quality of watering due to the watering trajectory closest to rectangular.
\end{abstract}

\section{Introduction}

Changing the water content in the growing environment of plants allows to control the production processes taking place in them. Optimization of the water regime in the active soil layer is ensured by planned watering with soil wetting to the depth of the main root system of agricultural crops [1].

Regular watering helps to maintain the required moisture content in the active soil layer, which is especially important for the growth and development of crops [2,3]. Given the above, it is worth considering and scientifically substantiating the water regime of the root layer when growing agricultural plants.

It should be noted that the existing irrigation systems consume $15-20 \%$ of water resources more of the required volume, which leads to some deterioration of hydrogeological-

*Corresponding author: melnichuckmitya@,yandex.ru 
reclamation conditions and, as a result, decreases the productivity of irrigated areas. The effectiveness of the development of irrigated agriculture is possible only in conjunction with the application of scientific and technical achievements in the field of irrigation reclamation and related fields of science and technology, focused on the rational use of water resources and obtaining consistently high yields of agricultural crops [4]. Therefore, the most important task of land reclamation science is the development and implementation of water-saving technologies into the practice of irrigated agriculture aimed at increasing the productive use of irrigation water [5].

Thus, the efficiency of the use of soil-climatic, material, technical and energy resources largely depends on the applied irrigation equipment and technologies, which, in turn, affect the processes of regulating the water regime of the soil, and, consequently, the ecological safety and productivity of agricultural crops [6].

The most common method of irrigation is sprinkling, since this method is as close as possible to the process of natural precipitation. During sprinkling, the plant is saturated with moisture, turgor increases and dissolution of nutrients improves, which contributes to better assimilation of nutrients by plants, regulation of the temperature of the soil surface layer and the surface air, washing off dust from the leaf surface, and improved respiration and photosynthesis $[7,8,9]$.

Every year sprinkling technology finds more and more application, even in areas with a favorable climate. Modern irrigation machines are focused on operation from a closed irrigation network, automated operation, multipurpose use, the use of control and management systems based on digital technologies. According to the principle of operation, existing water sprinklers are divided into frontal and circular.

Front-end machines are designed for watering rectangular and long fields. At the same time, in the process of operation, the entire structure moves linearly along the irrigated area with the help of electric motors. The disadvantage of these installations is that they cannot work in areas with difficult terrain, where the total slopes between three adjacent bogies exceed 5 $\%$.

The circular machines got their name due to the fact that the irrigation wing has a stationary support at one end (in the center of the field), and at the other end it has a support with wheels and an electric drive. These machines can work on areas with a slope of up to $15 \%$. Their disadvantages include impossibility to cover the entire surface of the field, as a result of which zones of insufficient moisture appear. This problem is solved by imposing one watering section on another one, considering the overlap coefficient, as a result of which waterlogged areas are formed. In this connection, machines of the circular type do not provide uniform distribution of precipitation over the irrigated area [13].

Thus, the existing water sprinklers cannot fully produce high-quality irrigation of agricultural land, due to the design features and the specific landscape on which they are used, forming zones with excessive and insufficient moisture [11]. The existing water sprinkler technique is applicable only in fields with a large area and an almost flat surface, but agriculture is constantly developing and due to limited land resources, crops are grown in hilly and mountainous areas $[12,13]$.

Also, production of products in greenhouses is gaining increasing development. For such cases, a small-sized technique is required that can work in areas with elevation differences. This technique exists in a very limited number, since watering with such samples does not meet the entire range of agro-technological requirements for irrigation. There is a positional water sprinkler (PWS) irrigation of which is organized positionally, with complete overlap of the irrigated areas to a width equal to half the diameter of the irrigated circle, which again leads to an uneven distribution of precipitation over the irrigated area. 
In this regard, the goal of this work is to develop a positional water sprinkler that ensures uniform distribution of precipitation over the entire irrigated area and reduces the consumption of water resources.

\section{Materials and methods}

To solve the problem of uneven distribution of water resources during irrigation of agricultural land, it is advisable to develop and manufacture a positional water sprinkler that has the ability to irrigate along a trajectory close to rectangular. In this case, the technological scheme of irrigation is simplified, the areas of excessive and insufficient moisture are reduced, which in turn leads to saving water resources and contributes to the optimal growth and development of plants.

In the course of theoretical research, the processes occurring during the operation of the developed water sprinkler were studied using the methods of mathematical analysis, graphic and mathematical modeling. Based on the data obtained, a prototype of a water sprinkler was designed and manufactured.

After that, experimental studies were carried out aimed at determining the main technical characteristics of the water sprinkler. The research was carried out according to the methodology developed in accordance with GOST ISO 7749-2-2004 Irrigation uniformity and test methods.

The tests were carried out on an asphalt site with a total slope of no more than $1 \%$ and free of obstacles to the free distribution of water. A coordinate was applied to the surface of the site and rain gauges were installed at intersections, with a step of $500 \mathrm{~mm}$. The sprinkler was located in the center of the selected area. The water was supplied through a hose where a liquid-consumption gauge was fixed. The readings from the gauge were transmitted to the Arduino board, which recorded the incoming signal and converted it to text format, providing data on instantaneous water flow $(1 / \mathrm{min})$ and total flow. The readings of the pressure of the supplied water were taken from a pressure gauge installed in the housing of the rotation unit. The experiment had three replications and the operating time of the water sprinkler was 30 minutes for each replication. After 30 minutes, the operation of the water sprinkler was stopped and the volume of water in each rain gauge was determined using a measuring cylinder with a volume of $250 \mathrm{ml}$.

\section{Results and discussion}

The developed water sprinkler is a frame skid mounted on runners with the help of support posts, which are connected in pairs by transverse rods, a platform fixed in the upper part of the frame skid and having a rotating assembly, which consists of a lower body and an upper body, pipe sections, wings located relative to each other at an angle of $120^{\circ}$, with sprinkler nozzles fixed at the ends, a block of gears performing the principle of a planetary mechanism (Fig. 1) [14].

The proposed water sprinkler works as follows. The water supply from the pipeline to the rotating assembly is carried out through the inlet nozzle, which is designed as a tangential inlet. Thanks to this solution, the flow of water is directed along the generatrix of the surface of the cylindrical body, creating a significant centrifugal effect. Heading along the horizontal arm of the water sprinkler, the water flow bifurcates and enters the wing of a small irrigation radius and into the transition unit, where the tee for fastening the sprinkler wings is installed. A driven gear is also rigidly fixed on the tee axis. In the lower part of the housing of the transition unit, a wheel is mounted with the possibility of rotation around the vertical axis, 
which acts as a support for the horizontal part of the water sprinkler and contributes to maintaining the inertia of movement. The flow of water moving along the transition unit and wings reaches the sprinkler nozzles, breaks up into drops, which create a reactive rotation force. At the same time, at the end of the wing of a small irrigation radius, a sprinkler head is installed, directed in the opposite direction, which also provides a reactive force for rotating the installation around the central axis, and covers the central part of the irrigated area increasing uniformity over the entire irrigated area. The reactive force created by the sprinkler nozzles is transmitted through the driven gear to the drive gear, which has a rigid fit on the axis of the water sprinkler, by means of the intermediate gear mounted for rotation around the axis of the attachment. Thus, the principle of the planetary mechanism is fulfilled, which ensures the irrigation trajectory close to rectangular.

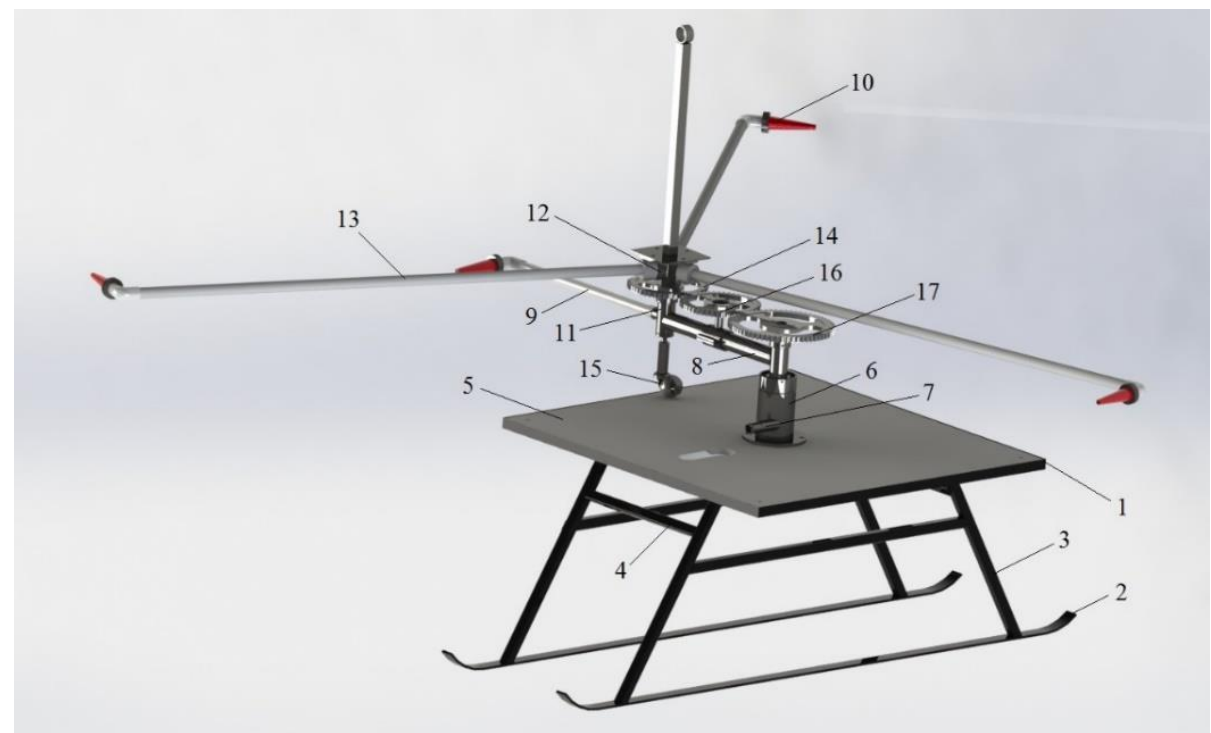

1 - frame skid; 2 - runners; 3 - support posts; 4 -transverse rods; 5 - platform; 6 - rotating assembly; 7 - inlet nozzle; 8 - horizontal arm; 9 - wing of a small irrigation radius; 10 - sprinkler nozzle; 11 - transition unit; 12 - tee for fastening the sprinkler wings; 13 - sprinkler wings; 14 driven gear; 15 - wheel; 16 - idler gear; 17 - drive gear.

Fig. 1. Positional water sprinkler.

Obtaining this trajectory is achieved by using the principle of planetary gear and is described by the following system of equations:

$$
\left\{\begin{array}{l}
x_{b}(t)=b \cdot \cos (\alpha(t))+l \cdot \cos \left(\frac{4 \pi}{3}+\beta(t)\right) \\
y_{b}(t)=b \cdot \sin (\alpha(t))+l \cdot \sin \left(\frac{4 \pi}{3}+\beta(t)\right)
\end{array}\right.
$$

where $b$ is the length of the horizontal section of the pipeline (the value of eccentricity), $\mathrm{m} ; \alpha$ is the angle of pitch relative to the drive pulley, $(\mathrm{rad} / \mathrm{sec}) ; \beta$ is the angle of pitch relative to the driven pulley, $(\mathrm{rad} / \mathrm{sec}) ; l$ is the length of the water sprinkler wings, $\mathrm{m} ; t$ is the water sprinkler operation time, sec.

On the basis of the presented system of equations in the Mathcad program, an irrigation trajectory was built for the proposed water sprinkler, shown in Figure 2. 


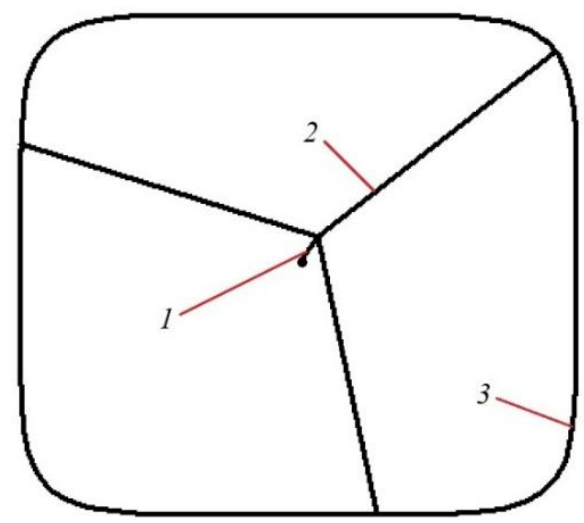

1 - carrier; 2 - water sprinkler wings; 3 - motion trajectory of the wing ends

Fig. 2. Irrigation trajectory of the water sprinkler.

The presented mathematical model describes the motion trajectory of the wing ends of the developed water sprinkler. Since there are sprinkler nozzles with a spray pattern of 60-800 at these points, the irrigation zone will correspond to the presented model. Moreover, this trajectory is a Lamé curve and is the closest one to a rectangle.

The performance of existing water sprinklers is largely determined by the irrigation zone, which is usually a circular path. In this connection, the motion trajectory of the sprinkler wing ends of a similar irrigated technique was also built in the Mathcad program. To compare the quality of irrigation, it was determined by the edges of the trajectory of the proposed water sprinkler and represented an inscribed circle (Fig. 3).

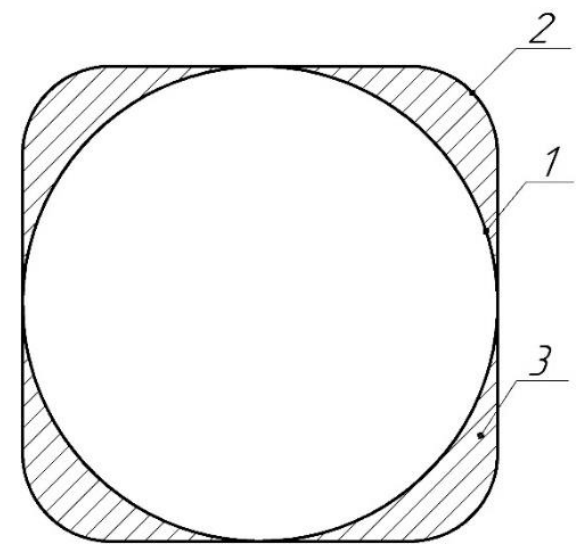

1 - irrigation trajectory of the circular sprinkler; 2 - irrigation trajectory of the proposed water sprinkler; 3 - additional irrigation area

Fig. 3. Comparison of irrigation trajectories.

Figure 3 shows that the irrigation trajectory of the proposed water sprinkler is the most optimal in comparison with the existing equipment that irrigates in a circle. Due to the fact that this trajectory tends to an equilateral rectangle, it is able to cover a large area in one irrigation cycle, while the area gain is achieved through the use of a planetary mechanism in the design of the water sprinkler. Additionally, irrigated plots make up $23.6 \%$ of the area described by a circular trajectory, while, in the case of existing water sprinklers, these plots 
will be zones with insufficient moisture, the share of which will be about $22 \%$ of the area of a rectangular irrigated area, while this figure will be less than $5 \%$ in the proposed trajectory.

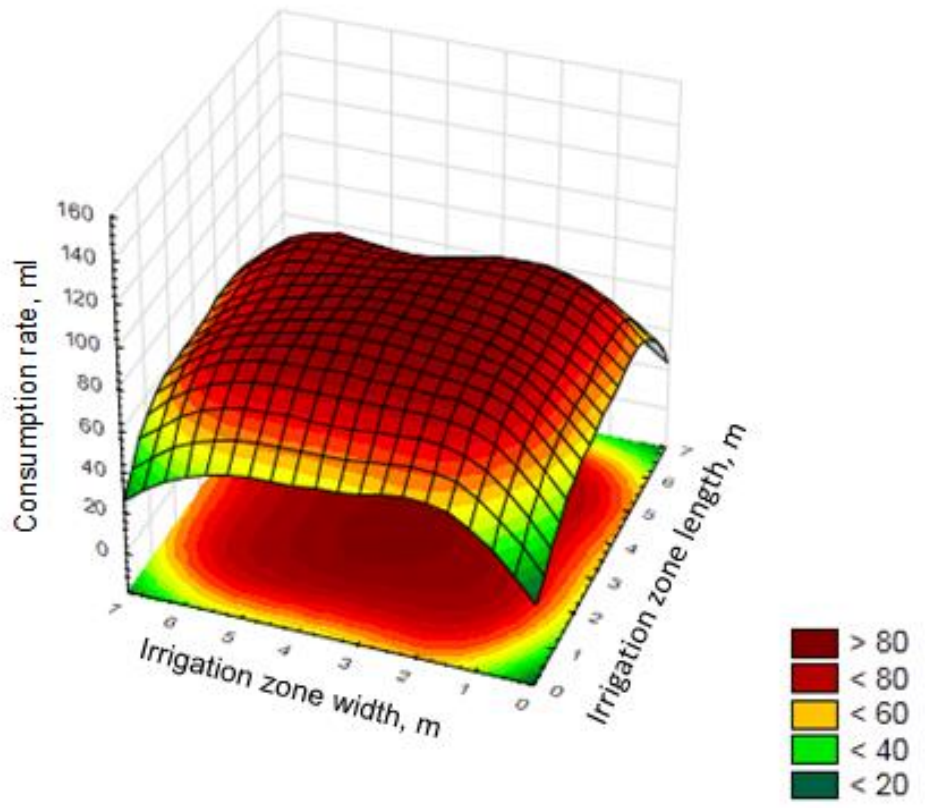

Fig. 4. Field water distribution.

To confirm the results of theoretical calculations and determine the parameters and operating modes of the experimental sample of the developed water sprinkler, its laboratory tests were carried out. The studies were carried out according to the developed methodology under constant weather conditions. The ambient temperature was $20^{\circ} \mathrm{C}$, the air velocity ranged from 1.5 to $3 \mathrm{~m} / \mathrm{s}$. As a result of the research, data on water distribution by rain gauges were obtained, which were grouped into a summary table, on the basis of which, using Statistica program, a graph of the field water distribution over the irrigated area was built (Figure 4).

Analysis of the graph shows that there is a high uniformity of field water distribution practically over the entire area and it is about $60 \mathrm{ml}$, while the zones of insufficient moisture with water distribution in the range from 20 to $40 \mathrm{ml}$ are located at the corners of the experimental site in the ranges from 0 to $0.5 \mathrm{~m}$ and from 6.5 to $7 \mathrm{~m}$. It is worth noting that the resulting trajectory allows to optimize the irrigation technology using overlap factors in large areas.

Since when irrigating large areas, it becomes necessary to install water sprinklers in such a way that no dry areas arise, irrigation systems are installed so that the trajectory of one water sprinkler overlaps with the trajectory of another one, that is, overlap zones are created. For water sprinklers operating on a circular irrigation trajectory, the most common layout is rectangular, however, with this layout, the proportion of overlaps from the total irrigated area can reach $50 \%$ [15]. Figure 5 shows a possible layout, on an elementary rectangular section of the field, the proposed water sprinkler and existing ones operating on a circular trajectory. 


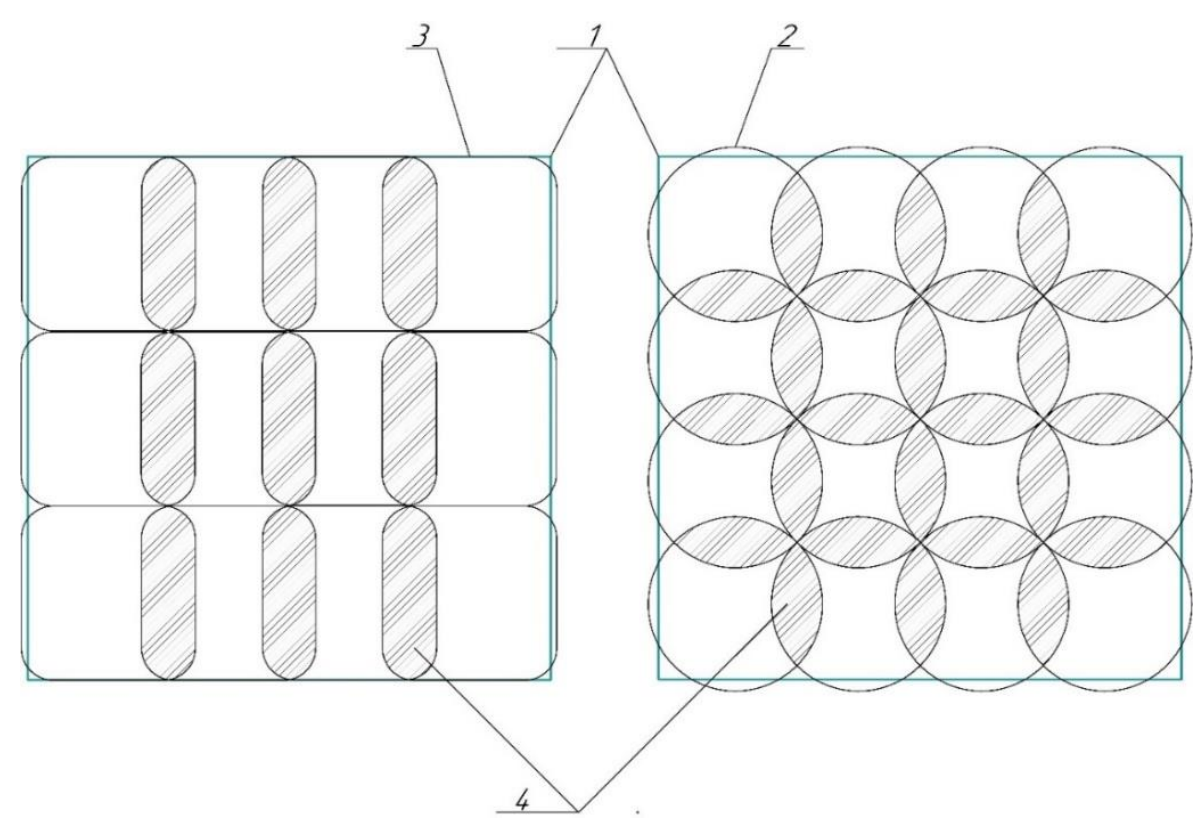

1 - field perimeter; 2 - irrigation trajectory for existing equipment; 3 - irrigation trajectory of the proposed water sprinkler; 4 - overlap zones

Fig. 5. Useful irrigated area and overlap zones.

Figure 5 shows that with the same field area, water sprinklers operating on a circular trajectory and placed accordingly have the required overlap zones with an area of about 38 $\%$ of the total field area, while this indicator for the proposed water sprinkler is lower by about $26 \%$ and accounts for about $28 \%$ of the total field area.

\section{Conclusion}

To obtain consistently high yields of agricultural crops, the determining factor is the availability of the required amount of moisture and nutrients in the root layer of the soil. Maintaining an optimal water regime is achieved through regular irrigation, while the most common positional irrigation systems have a circular irrigation trajectory. These systems have several disadvantages, in particular the formation of zones of insufficient moisture and waterlogging.

To solve these problems, a positional water sprinkler has been developed, which has the closest rectangular irrigation trajectory. The use of this water sprinkler will improve the quality of irrigation by reducing areas of low moisture by more than $77 \%$, thereby contributing to the creation of favorable conditions for optimal growth and development of crops. And its application on large areas using the overlapping irrigation scheme will reduce the consumption of water resources by reducing the total area of overlap zones by more than $25 \%$. Based on this, it can be concluded that the application of the proposed solution leads to a reduction in costs for water resources, as well as an increase in the uniformity of water distribution over the irrigated area.

\section{References}


1. L. Chu., Y. Kang., X. Chen., X. Li, Nongye Gongcheng Xuebao, 29 (7), 76-82 (2013) 10.3969/j.issn.1002-6819.2013.07.010

2. X.Wang, W.Cai, J.Hu, Comparative Revenue (2020)

3. Shandong Province in China, Agricultural Sciences, 11, 1-16 (2020) 10.4236/as. 2020.111001

4. A. Mulu, T. Alamirew, Global Journal of Biology. 1(1), 17-21 (2012)

5. S.Q. Yuan, R.O. Darko, X.Y. Zhu, et al., Int J Agric \& Biol Eng, 10(1), 72-79 (2017)

6. S. Maroufpoor, E. Maroufpoor, M. Khaledi, Agricultural Water Management, 223, 105691 (2019)

7. M. Shiva Shankar, A.V. Ramanjaneyulu, T.L. Neelima, Anup Das, Sprinkler Irrigation - An Asset in Water Scarce and Undulating Areas, 259-283 (2018)

8. D.K. Dehkordi, Advances in Environmental Biology, 8 (13), 781-786 (2014)

9. V.S. Teterin, D.S. Melnichuk, N.N. Novikov, Science in Central Russia, 6 (36), 20-28 (2018)

10. W. Zhao, J.Li, Y.Li, et al., Agricultural and Forest Meteorology, 161, 116-122 (2012)

11. X. Haonan, Q. Yang, L. Yu, et al., Nongye Gongcheng Xuebao, 33 (22), 84-91 (2017)

12. N. Boja, F. Boja, A. Teuşdea, P.A.Dărău, Scientific Papers. Series A. Agronomy, LVI, 453-458 (2013)

13. S. A. O'Shaughnessy, S.R. Evett, P. Colaizzi, et al., Applied Engineering in Agriculture, 35 (6), 837-852 (2019) (doi: 10.13031/aea.13128)

14. A.A. Kalashnikov, B.M. Kurtebaev, A.E. Baizakova, P.A. Kalashnikov, Journal of pharmaceutical sciences and research, 9 (9), 1498-1504 (2017)

15. D.S. Melnichuk, Technical support of agriculture, 1 (2), 46-50 (2020)

16. L. Zhang, G. Merkley, K. Pinthong, Irrigation Science, 31 (2011) 10.1007/s00271-0110294-0 